$$
\begin{array}{r}
\text { https://doi.org/10.52696/WIVS9084 } \\
\text { Reprints and permission: } \\
\text { The Malaysian English Language Teaching Association } \\
\text { Soe Marlar Lwin marlarlwin@suss.edu.sg }
\end{array}
$$

\title{
Oral Corrective Feedback in a Chinese University EFL Classroom Context
}

\author{
Soe Marlar Lwin \\ Singapore \\ Dong Yang \\ Liaoning \\ China
}

Singapore University of Social Sciences

\begin{abstract}
This study examines the oral corrective feedback $(\mathrm{CF})$ used in a Chinese university EFL classroom context, focusing on the lessons that teach the use of English articles through narrative stimulus activities. It adopts a mixed-methods research design which includes pre- and post-tests, lesson activities for providing oral corrective feedback, a questionnaire, and interviews with students. Results show that elicitation was the most frequently used CF type, while metalinguistic feedback was used least frequently by the teacher. In general, the Chinese university EFL students surveyed in this study had positive attitudes towards receiving CF. Nonetheless, they perceived elicitation as the most effective CF type and metalinguistic feedback the least effective, which interestingly mirrors the two CF types used most and least frequently by their teacher. The findings shed some light on the CF practices and students' attitudes towards such practices in a Chinese university EFL classroom context, and offer implications for teachers on using certain types of CF.
\end{abstract}

\section{KEYWORDS: Oral Corrective Feedback, Chinese University Students, EFL, Learners' Attitudes}

\section{INTRODUCTION}

Studies of oral corrective feedback $(\mathrm{CF})$ can be on conversational feedback, which occurs in naturalistic settings, or pedagogic feedback, which predominates in classroom settings. This study focuses on pedagogic feedback found commonly in classroom discourse as teachers' indication to a learner that their use of the target language contains an error. During a lesson, teachers have to constantly make decisions about how and when to provide CF. Such decisions or choices of CF are affected by various contextual features, such as teachers' knowledge and preference of different types of CF in relation to their effectiveness, the profiles of learners, and their attitudes towards receiving $\mathrm{CF}$. This study examines the $\mathrm{CF}$ practices found in a Chinese university EFL classroom context. The study aims to find out the types of CF used and whether the use of CF has 
an effect on students' learning of a particular grammatical item, namely the English articles "a", "an" and "the". Students' attitudes towards receiving different types of CF are also explored.

The English articles "a", "an" and "the" are purposefully chosen as the target linguistic feature. As a classifier language, Mandarin, the native language (L1) of learners in this study, has no definite or indefinite articles. Accurate use of English articles can therefore be complex and challenging for speakers of such "article-less languages" (Crosthwaite, 2016). Moreover, studies that examined the difficulty faced by learners of different L1s when using English articles have shown possible L1 influence - e.g., tendency to omit definite articles by learners whose L1 is a language without articles (Chrabaszcz \& Jiang, 2014). With regard to the roles of CF in teaching and learning of English articles, Yilmaz's (2013) study revealed that different types of CF had differential effects on learners' acquisition of the articles. Yilmaz (2013) examined the use of English articles by university EFL students in Turkey during oral production tasks. Focusing on the lessons teaching Chinese university EFL learners the use of English articles, this study seeks to address the following research questions:

1. What types of CF were used by the teacher?

2. Was the teacher's use of CF effective for students' learning of English articles?

3. What were the attitudes of the students who received CF towards the types of CF used by their teacher?

\section{LITERATURE REVIEW}

To situate the study in the field, a review was done on some existing studies that examined types of CF or effectiveness of CF and learners' preferences.

\section{Types of $C F$}

$\mathrm{CF}$ can be categorized into various types. For example, in their seminal study of the relationship between teachers' CF and learners' uptake in French immersion classrooms at a primary level, Lyster and Ranta (1997) identified six different CF types - namely, explicit correction, recasts, clarification requests, metalinguistic feedback, elicitation, and repetition. Subsequently, Ranta and Lyster (2007) classified them into two broad categories: reformulations and prompts. Recasts and explicit correction are subsumed under reformulations, which provide learners with target reformulation of their non-target output. The other four types are included under the prompts category, which pushes learners to self-repair. Ellis (2006) explains the former as input-providing and the latter as output-pushing. CF has also been classified into implicit vs explicit feedback (Ellis et al., 2006; Li \& Vuono, 2019). Recasts are a typical form of implicit feedback, whereas metalinguistic explanations are a typical form of explicit feedback (Ellis et al. 2006).

With regard to the classroom context, a number of studies have examined the distribution of different $\mathrm{CF}$ types used by teachers across a range of instructional settings. For example, Llinares and Lyster (2014) compared the frequency and distribution of three different types of CF (recasts, prompts and explicit correction) at the $4^{\text {th }}-5^{\text {th }}$ grade level across three instructional settings: (i) two content and language integrated learning (CLIL) classrooms in Spain with English as the target language; (ii) four French immersion classrooms in Quebec; and (iii) three Japanese immersion classrooms in the US. Their findings revealed that teachers in all three settings used recasts, prompts and explicit correction in similar proportions, with recasts being the most frequent, followed by prompts, and then explicit correction. For EFL classroom settings in Asia, a recent 
example was the study done by Ha and Murray (2020). They examined the beliefs and practices of six Vietnamese primary EFL teachers regarding CF. The findings based on their classroom observations showed recasts as the most frequently used CF type, although the teachers reported that they believed prompts were the more effective and favourable CF type. Comparing the use of CF in American ESL and Chinese EFL classrooms, Wang and Li (2021) also found that recast was the most preferred in both settings.

In general, studies of the distribution of different CF types in the classroom context have revealed one overall pattern: i.e. recasts seem to be the most frequently used CF type by teachers (Brown, 2016). However, Lyster et al. (2013) have warned that there can be considerable variation across different contexts and recasts may not necessarily be the most frequently used type of CF across all instructional settings. Indeed, there have been exceptions. For example, Yang (2009) examined the distribution of teachers' CF in a Chinese high school and found that, unlike the findings from the studies done in other contexts, prompts were the most frequently used type of $\mathrm{CF}$ in that Chinese high school EFL classroom context. Since Yang's (2009) study, a few more studies have been done on the use of CF in Chinese EFL classroom contexts - e.g., Xu (2012), Yang and Lyster (2010) and Zhu and Wang (2019). None, however, has examined teachers' CF practices during lessons on the use of English articles.

\section{Effectiveness of $C F$ and Learners' Preferences}

Studies have also examined the effectiveness of CF. For example, Gooch et al. (2016) tested the effectiveness that recasts and prompts had on learning of English / / / by Korean adult EFL learners. In their study, the recast group demonstrated significant gains in controlled production while the prompt group demonstrated stronger performance in controlled and spontaneous production. Gooch et al. (2016) suggested that recasts might be more useful for learners with lower proficiency as they provide learners with the exemplars needed. Focusing on another grammatical item, regular past tense, Ellis et al. (2006) examined the effects of recasts and metalinguistic feedback. Their study revealed that the metalinguistic feedback (or explicit feedback) was more effective than recasts (implicit feedback). However, Yang and Lyster's (2010) study suggested that there were significant differences between CF types in improving adult EFL learners' use of past tense forms. Their study compared the effects of recasts, prompts and no CF on the use of regular and irregular past tense forms with adult EFL students in China. They found that while prompts and recasts were equally effective in improving Chinese adult EFL learners' accurate use of irregular past-tense forms, prompts were more effective in improving learners' use of regular past-tense forms. Hence, it can only be concluded that although studies have shown CF to be beneficial, it is important to note the variability in their results.

With regard to learners' preferences, many studies have confirmed leaners' positive attitudes towards receiving CF. However, there are differences in terms of the type(s) of CF preferred by learners from different contexts. For example, Yoshida's (2008) study found that Japanese learners in Australia preferred prompts to recasts, as they wanted time to self-repair. Comparing the firstyear and second-year American university students' preferences, Brown (2009) similarly found that the second-year students preferred indirect CF types to direct CF types. On the other hand, Mohammadnia and Irandust's (2015) study, which examined the Iranian adult EFL learners' attitudes towards six CF types, revealed that metalinguistic feedback was most preferred. Synthesizing all empirical studies of teacher and student beliefs and attitudes towards CF, Li (2017) in his meta-analysis concluded that learners were largely positive about CF. However, 
variability in results and contextual factors should be noted, suggesting a need for more studies in this area.

\section{METHODOLOGY}

This study adopted a mixed-method approach and a variety of research instruments were used to collect the data. Pre- and post-tests, narrative stimulus activities and a questionnaire were used as instruments to collect the quantitative data, while semi-structured interviews were used to elicit the qualitative data to complement and triangulate the quantitative data. The entire data collection process lasted approximately seven weeks.

\section{Participants}

The study involved two female teachers of similar age (38 and 40 years old) and 67 students (with ages ranging from 21 to 23 years) enrolled in an EFL class in a university in Liaoning, a province in the north-eastern region of mainland China. One of the teachers (Teacher A) holds a Doctorate degree in Education, while the other (Teacher B) holds a Master's degree in English Education, which, currently, is the minimum qualification required to teach in most Chinese universities. They each had about 15 years of teaching experience. The 67 students were from two intact classes taught by the teachers. There were 34 students in the class taught by Teacher A, and 33 students taught by Teacher B. All of them were Year Three university students majoring in English. Thirteen of them were male and 54 students were female. They were all born and educated in China, and spent at least twelve years studying in Chinese schools before they were admitted to this university.

The lessons chosen for this study were part of the comprehensive English course, a foundational course that all English majors must take. The course aims to develop students' ability to use English accurately and appropriately. It focuses on the explanation of grammar points, reading comprehension and vocabulary activities, and frequently uses story-retelling or narrative stimulus activities to practice specific grammar points and/or vocabulary during lessons. Lessons are held twice a week, each lasting two hours. For this study, both teachers were asked to use 30 minutes of each of their comprehensive English lessons for the same narrative stimulus activities designed to elicit the use of English articles from the learners. Each narrative stimulus activity contains a short story, and the teacher asks their students to retell it in turn after reading the story.

Prior to beginning data collection, the first author briefed the two teachers on how to provide CF. Teacher A and Teacher B were randomly assigned to the control and treatment groups. Teacher A's class was designated as the control group $(n=34)$, and the class taught by Teacher (B) became assigned as the treatment group $(n=33)$. Teacher B was asked to give CF particularly on the students' errors in the use of English articles (treatment group), whereas Teacher A was asked not to give any CF on the students' errors in the use of English articles (control group). However, to maintain the natural classroom interaction between the teacher and students, both teachers were allowed to give CF on the students' errors in any other grammatical items (e.g., verb tenses, singular/plural nouns, etc.) during their lessons. The two teachers' uses of CF for the errors in those other grammatical items were excluded from the data collected for this study. 
Pre- and Post-Tests

All students $(\mathrm{n}=67)$ participating in the study took a pre-test and a post-test, which established a baseline of their knowledge of the target structure, i.e., the use of English articles. Adapted from the test instruments used in Liu and Gleason (2002), the pre-test and post-test were error correction tests, each involving 15 error correction items. To ensure validity, the same measures were used in designing the pre-test and post-test. For example, each item in the pre- and post-tests was a sentence that contained an error in article use, e.g., "I saw a movie last night. I forgot the name of movie." The full score for each test was 15 marks and each correct answer received one mark. Incorrect or missing answers were given zero marks. The two tests were also designed to have the same test answer distribution (i.e., the types and frequencies of English articles which need to be corrected) to ensure that they had similar difficulty levels. The pre-test was scheduled in Week 1 of the data collection while the post-test was completed in Week 6 . The total time allowed for the pre-test and post-test was 10 minutes each. The tests were administered to all the students simultaneously in their respective classrooms.

\section{Narrative Stimulus Activities}

Starting from Week 2 of data collection, the control group and treatment group each completed a total of eight activities (two per week) over a period of four weeks. It was decided considering the time the study had for data collection, and the frequency and duration of lessons the university had scheduled for this English course in the students' timetables. By keeping the frequency and duration of lessons in the students' timetables, learning of English happened as usual for these students. The more representative the type of learning that happens in classroom studies, the higher the validity $(\mathrm{Li}, 2018)$.

Adapted from Sheen (2007), each activity lasted 30 minutes and contained a narrative stimulus to elicit English article errors from the students who were asked to read the narrative and then retell it to the class. Below is the first narrative stimulus given as an example.

There was once a crow who stole a piece of cheese from a kitchen window. She flew off with the cheese to a nearby tree. A fox saw what the crow had done, and he walked over to the tree. 'Oh, Mistress Crow, you have such lovely black feathers, such little feet, such a beautiful yellow beak, and such fine black eyes! You must have a beautiful voice. Would you please sing for me?' The crow felt very proud. She opened her beak and sang CAWCAW-CAW-CAW. Of course, the cheese fell down, and the fox ate the piece of cheese.

Source: The Fox and The Crow. (n.d.). Aesop's Fables.

The lessons with narrative stimulus activities conducted by Teacher B were observed and audiorecorded. Those conducted by Teacher A were only observed to ensure that there was no CF provided on the students' incorrect uses of English articles.

\section{Questionnaire and Semi-Structured Interviews}

Adapted from Zhang and Rahimi (2014), a questionnaire was designed to measure students' attitudes towards different CF types. The items were randomly ordered and followed a five-point Likert scale ranging from Strongly Agree/Very Effective to Strongly Disagree/Very ineffective (see Appendix A). These seven questionnaire items has a Cronbach's alpha of 0.893, which is acceptable reliability. In the same week when the post-test was conducted, the questionnaire in English was administrated to the student participants in the treatment group $(n=33)$ after they 
completed the post-test. The participants were asked to tick the most appropriate responses to the seven questions on the questionnaire, and were reassured that their responses would remain confidential and never be revealed to their teacher. They were allowed to ask questions in Chinese verbally and use their dictionaries when responding to the questionnaire.

Next, semi-structured interviews were designed to elicit the qualitative data and supplement the data collected from the questionnaire. Simple random sampling was used to select five respondents from the treatment group. Each interview consisted of three questions that were designed to capture the respondents' attitudes towards different CF types and to allow them to elaborate on their views with some flexibility. Besides these pre-designed questions, topics initiated by individual interviewees or that arose naturally from the responses were also pursued further. The interviews were conducted face-to-face with each interviewee in Mandarin, the interviewees' L1, to allow them to express their attitudes towards receiving different $\mathrm{CF}$ types more freely (i.e., without feeling restricted by their limited oral English proficiency) and to ensure the quality of the interview data (Dörnyei, 2007). Each interview lasted for about 10 minutes. All sessions were audio-recorded for later verbatim transcription, coding and analysis.

\section{Data Analysis}

First, the audio-recordings of classroom interaction during the eight narrative stimulus activities conducted by Teacher B were coded to answer the first research question: What types of CF were used by the teacher? Lyster and Ranta's (1997) frequently-cited error treatment sequence was employed as the coding scheme. According to Lyster and Ranta (1997), an error treatment sequence starts with a learner's ill-formed utterance, which contains at least one error. The erroneous utterance is followed either by the teacher's corrective feedback or topic continuation. Following this, the error treatment sequences in the recorded classroom interaction were extracted. If CF is provided, it is classified into one of the Lyster and Ranta's (1997) classifications of (6) CF moves: explicit correction, recasts, clarification requests, metalinguistic feedback, elicitation, and repetition. Table 1 shows a sample coding of classroom interaction.

Table 1. Sample Coding of Classroom Interaction

\begin{tabular}{|c|c|c|}
\hline $\begin{array}{l}\text { Instance of } \\
\mathrm{CF}\end{array}$ & $\begin{array}{l}\text { Error Treatment Sequence Extracted from } \\
\text { Classroom Interaction }\end{array}$ & CF Type \\
\hline 1 & $\begin{array}{l}\text { Student (S): She fly to a tree with a piece of cheese. } \\
\text { Teacher (T): With the piece of cheese }\end{array}$ & Recast \\
\hline 2 & $\begin{array}{l}\text { S: You have a such lovely feathers. } \\
\text { T: You have... }\end{array}$ & Elicitation \\
\hline 3 & $\begin{array}{l}\text { S: You must have the beautiful voice. } \\
\text { T: Have the beautiful voice? }\end{array}$ & Repetition \\
\hline 4 & $\begin{array}{l}\text { S: And cheese fell down. } \\
\text { T: And the cheese fell down. }\end{array}$ & Recasts \\
\hline 5 & $\begin{array}{l}\text { S: The fox ate a piece of cheese. } \\
\text { T: The fox ate... }\end{array}$ & Elicitation \\
\hline 6 & $\begin{array}{l}\text { S: Crow feels very proud. } \\
\text { T: The crow is already mentioned, and here you should use "the". }\end{array}$ & $\begin{array}{l}\text { Explicit } \\
\text { Correction }\end{array}$ \\
\hline
\end{tabular}

Next, the two groups' pre-test and post-test scores were analysed both descriptively and inferentially to answer the second research question: Was the teacher's use of CF effective for students' learning of English articles? The sample size, range, mean and standard deviation of the two groups' pre-test and post-test scores were examined. Then independent-samples t-tests were 
run to statistically compare the differences in the two groups' scores on the pre-test and post-test respectively.

Finally, quantitative data obtained from the questionnaire and qualitative data from the semistructured interviews were examined to address the third research question: What were the attitudes of the students who received CF towards the types of CF used by their teacher? The seven items in the questionnaire were coded in the terms of the participants' responses to each item using a 5-point Likert-scale: 1= strongly disagree/very ineffective, $2=$ disagree/ineffective, $3=$ neutral, 4= agree/effective, and 5= strongly agree/very effective. The points for each item, as well as the distribution for each item, were compared to interpret the students' attitudes towards different types of CF. Recording of the semi-structured interviews was transcribed in the original interview language before they were translated into English. Then the thematic analysis was done by examining the transcripts closely to identify common themes or patterns for generalisations regarding students' attitudes towards different types of CF.

\section{FINDINGS AND DISCUSSION}

Addressing the three research questions, the results are presented and discussed below.

\section{Distribution of CF Types Used by the Treatment Group's Teacher}

The results show that the teacher of the treatment group gave comparable numbers of $\mathrm{CF}$ in the eight lesson activities. Table 2 gives an overview of the number of $\mathrm{CF}$ instances given by the teacher for each activity.

Table 2

Number of CF Given by the Teacher for Each Activity

\begin{tabular}{cccccccccc}
\hline & A1 & A2 & A3 & A4 & A5 & A6 & A7 & A8 & Total \\
\hline $\mathrm{N}$ & 42 & 45 & 44 & 45 & 44 & 43 & 46 & 47 & 356 \\
\hline
\end{tabular}

Note: N=Number; A1=Activity1; A2=Activity2; A3=Activity3; A4=Activity4; A5=Activity5; A6=Activity6; A7=Activity7; A8=Activity 8

Table 3 more specifically presents results for the distribution of the different types of CF given for each activity. Notably, elicitation was found to be the most frequently used CF type across the eight activities. Besides elicitation, the teacher used at least three other types of CF in each of these activities. However, metalinguistic feedback was strikingly missing in all the activities.

Table 3

Distributions of Different CF Types

\begin{tabular}{ccccccc}
\hline A & Rep & E & EC & MF & Rec & CR \\
\hline A1 & 6 & 24 & 3 & 0 & 9 & 0 \\
& $(14 \%)$ & $(57 \%)$ & $(7 \%)$ & $(0 \%)$ & $(22 \%)$ & $(0 \%)$ \\
\hline A2 & 8 & 22 & 4 & 0 & 10 & 1 \\
& $(18 \%)$ & $(49 \%)$ & $(9 \%)$ & $(0 \%)$ & $(22 \%)$ & $(2 \%)$ \\
\hline A3 & 8 & 25 & 3 & 0 & 8 & 0 \\
& $(18 \%)$ & $(57 \%)$ & $(7 \%)$ & $(0 \%)$ & $(18 \%)$ & $(0 \%)$ \\
\hline A4 & 9 & 25 & 2 & 0 & 9 & 0 \\
& $(20 \%)$ & $(56 \%)$ & $(4 \%)$ & $(0 \%)$ & $(20 \%)$ & $(0 \%)$ \\
\hline A5 & 7 & 24 & 0 & 0 & 11 & 2 \\
& $(16 \%)$ & $(55 \%)$ & $(0 \%)$ & $(0 \%)$ & $(25 \%)$ & $(4 \%)$ \\
\hline
\end{tabular}




\begin{tabular}{ccccccc}
\hline A6 & 4 & 27 & 3 & 0 & 9 & 0 \\
& $(9 \%)$ & $(63 \%)$ & $(7 \%)$ & $(0 \%)$ & $(21 \%)$ & $(0 \%)$ \\
\hline A7 & 7 & 26 & 3 & 0 & 9 & 1 \\
& $(15 \%)$ & $(57 \%)$ & $(6 \%)$ & $(0 \%)$ & $(20 \%)$ & $(2 \%)$ \\
\hline A8 & 10 & 23 & 2 & 0 & 10 & 2 \\
& $(22 \%)$ & $(49 \%)$ & $(4 \%)$ & $(0 \%)$ & $(21 \%)$ & $(4 \%)$ \\
\hline M & 7 & 25 & 3 & 0 & 9 & 1 \\
& $(17 \%)$ & $(55 \%)$ & $(6 \%)$ & $(0 \%)$ & $(21 \%)$ & $(2 \%)$ \\
\hline
\end{tabular}

Note: A=Activity; A1=Activity1; A2=Activity2; A3=Activity3; A4=Activity4; A5=Activity5; A6=Activity6; A7=Activity7; A8=Activity8; M=Mean; Rep=Repetition; E=Elicitation; EC=Explicit Correction; $\mathrm{MF}=$ Metalinguistic Feedback; Rec $=$ Recasts; $\mathrm{CR}=$ Clarification Requests

Results for the aggregated numbers and percentages of the six CF types given during the activities are presented in Table 4 . As can be seen, elicitation was the most frequently used CF type by the teacher $(55 \%)$, while metalinguistic feedback was not used at all $(0 \%)$. Recasts $(21 \%)$ and repetition $(16 \%)$ ranked the second and third most frequently used CF type respectively, while explicit correction $(6 \%)$ and clarification requests $(2 \%)$ were in the fourth and fifth places.

Table 4

Distributions of CF Types (Total for All Activities)

\begin{tabular}{cccccccc}
\hline & Rep & E & EC & MF & Rec & CR & Total \\
\hline $\mathrm{N}$ & 59 & 196 & 20 & 0 & 75 & 6 & 356 \\
\hline $\mathrm{P}$ & $16 \%$ & $55 \%$ & $6 \%$ & $0 \%$ & $21 \%$ & $2 \%$ & $100 \%$ \\
\hline
\end{tabular}

Note: $\mathrm{N}=$ Number; $\mathrm{P}=$ Percentage; Rep=Repetition; $\mathrm{E}=$ Elicitation; $\mathrm{EC}=$ Explicit Correction; $\mathrm{MF}=$ Metalinguistic Feedback; Rec=Recasts; $\mathrm{CR}=$ Clarification Requests

As discussed earlier, the overall pattern found in the literature is recasts being the type of CF most frequently used by teachers in the classroom (Brown, D. 2016), with only a few exceptions such as Yang (2009), which found prompts as the most frequently used type of CF, and Xu (2012), which found explicit corrections as the most frequently used type, in their studies. The findings from the present study add another exception to the general pattern. In this study also conducted in a Chinese university EFL context, recasts constitute only the second largest category, accounting for $21 \%$ of the total number of teacher's CF sequences (see Table 4). The most frequently used type of CF in this study is elicitation (55\%). Unlike recasts, elicitation is an output pushing CF form. It withholds correct forms and allows the learner to eventually do self-repair. Thus, it is possible that through the use of elicitation the teacher was providing more opportunities for these adult intermediate learners of English to be engaged in the negotiation of form for the development of accuracy in using the English articles.

\section{Effectiveness of CF for Learning of English Articles}

The students' pre-test and post-test scores were anonymized, and renamed as $\mathrm{C}+$ number (e.g., $\mathrm{C} 1$, $\mathrm{C} 2, \mathrm{C} 3$ ) for the control group and $\mathrm{T}+$ number (e.g., T1, T2, T3) for the treatment group.

Pre-test scores:

An independent-sample t-test was run on their pre-test scores to see if there was any statistically significant difference between these two groups in their use of English articles. Table 5 shows the descriptive statistics of the two groups' pre-test scores. 
Table 5

Descriptive Statistics of the Two Groups'Pre-test Scores (max score: 15)

\begin{tabular}{lllllll}
\hline & $\mathrm{N}$ & Mean & Median & Mode & SD & Range \\
\hline CG & 34 & 9.53 & 9.50 & 9.00 & 1.99 & 9.00 \\
\hline TG & 33 & 9.52 & 10.00 & 10.00 & 2.02 & 9.00 \\
\hline
\end{tabular}

Note: $\quad \mathrm{CG}=$ Control Group; $\mathrm{TG}=$ Treatment Group; $\mathrm{N}=$ Sample Size; $\mathrm{SD}=$ Standard Deviation

It can be seen in Table 5 that the two groups' pre-test scores were different in the mean, median, mode, and standard deviation. Following this, an independent-sample $t$-test between the two groups' pre-test scores was performed to examine whether there were statistically significant differences in the use of English articles between the groups prior to the treatments. The statistical procedures were conducted by SPSS (version 22.0) and the alpha value was set at .05. Table 6 presents the results obtained from the statistical procedure.

Table 6

Inferential Statistics of the Two Groups' Pre-test Scores

\begin{tabular}{llll}
\hline & df & T & $\operatorname{Sig}(2$-tailed $)$ \\
\hline Pre-test & 65 & 0.029 & 0.997 \\
\hline
\end{tabular}

The Sig. was 0.997 , which was larger than the alpha value. It was concluded that there was no statistically significant difference between the two groups in the pre-test scores, i.e., the control group and treatment group had similar proficiency levels and were comparable in the use of English articles before the study.

Post-test scores:

Next, the descriptive statistics of the two groups' post-test scores are shown in Table 7, revealing differences in the two groups' mean, median, mode, standard deviation, and range. Results for the treatment group were higher across these categories, suggesting that students in this group did better on the post-test in general.

Table 7

Descriptive Statistics of the Two Groups'Post-test Scores

\begin{tabular}{ccccccc}
\hline & $\mathrm{N}$ & Mean & Median & Mode & SD & Range \\
\hline CG & 34 & 9.56 & 9.50 & 9.00 & 1.97 & 9.00 \\
\hline TG & 33 & 10.12 & 10.00 & 11.00 & 2.00 & 8.00 \\
\hline
\end{tabular}

Note: $\quad \mathrm{CG}=$ Control Group; $\mathrm{TG}=$ Treatment Group; N=Sample Size; SD=Standard Deviation

However, it is important to find out whether these differences are statistically significant before conclusions can be made about the effectiveness of corrective feedback on the performance of students in the treatment group. Therefore, an independent-sample $t$-test was run to compare the differences between the two groups' scores in the post-test. Table 8 shows the results from the statistical analysis of the two groups' post-test scores.

Table 8

The Inferential Statistics of the Two Groups'Post-test Scores

\begin{tabular}{cccc}
\hline & df & T & Sig(2-tailed) \\
\hline Post-test & 65 & -1.160 & 0.250 \\
\hline
\end{tabular}


The Sig. was 0.250 , which was larger than the alpha value. It indicates that there was no statistically significant difference in the post-test scores between the control group and treatment group, suggesting that the two groups had similar proficiency levels in the use of English articles at the end of the study.

Although the descriptive statistics analysis of the pre-test and post-test scores of the treatment group show some improvement in the means (from 9.52 to 10.12 marks), the results of inferential statistics show there was no statistically significant difference in the two groups' post-test scores. Factors such as the length of treatment sessions and difficulty of learning English articles could have mediated the effects of CF in this Chinese university EFL classroom context.

The present study consisted of only eight treatment sessions for the treatment group, each lasting 30 minutes. In Ammar and Spada's (2006) study, for example, there were a total of 12 instructional intervention sessions of 30-45 minutes each in, and they found that the groups that received corrective feedback outperformed the group that did not. Similarly, in a study investigating the impact of oral corrective feedback on the writing of adult ESL students in New Zealand, Erlam, Ellis and Batstone (2013) found that learners were able to correct themselves in article use and past tense verb form only over time in the delayed post-test. These learners received oral feedback twice through conferencing, once after a text reconstruction task and again after completing another text reconstruction task. Hence, the relatively short length of the treatment in this study could possibly be a factor contributing to the results of no statistical significance between the posttest scores.

Complexity in learning English articles may be another factor contributing to the results in this study. Earlier studies on the effects of CF on the learning of English articles, e.g., Yilmaz (2013), have suggested that the degree of explicitness is a key factor that influences the effectiveness of CF. Results from the present study show that the teacher in the Chinese university EFL classroom did not use any metalinguistic feedback $(0 \%)$, which is a typical form of explicit feedback type ( $\mathrm{Li}$ \& Vuono, 2019). Explicit correction, another form of explicit feedback, was also used only 6\% by the teacher in this study. Instead, the teacher largely used elicitation (55\%), recast (21\%), and repetition (16\%). Recasts are a typical form of implicit feedback that may not be facilitative to learning English articles (Yilmaz, 2013). As for the use of elicitation and repetition, on the one hand, the teacher could be providing more opportunities for these adult intermediate learners to engage in the negotiation of form for the development of accuracy in using English articles through these less explicit feedback type. However, the complexity in learning definite and indefinite articles in English seems to require pedagogical practices that utilize more explicit feedback (such as metalinguistic feedback and explicit corrections) for the effectiveness to be more significant. Although more studies still need to to be conducted to examine more closely the use of implicit and explicit feedback according to the types of articles by teachers in the Chinese university EFL context, overall very little use of explicit feedback by the teacher in this study may be one plausible explanation for the lack of statistically significant improvement for the treatment group.

\section{Learners' Attitudes towards Different Types of CF}

Results for the responses to each questionnaire item are shown in Table 9. As can be seen in the table, $33 \%$ of the student participants regarded elicitation very effective, making it the most preferred CF type. Metalinguistic feedback was the least preferred type, as $27 \%$ of them thought it was very ineffective. 
Table 9

Distributions of Each Questionnaire Item

\begin{tabular}{cccccc}
\hline & $\begin{array}{c}\text { Strongly agree/ } \\
\text { Very effective }\end{array}$ & $\begin{array}{c}\text { Agree/ } \\
\text { Effective }\end{array}$ & Neutral & $\begin{array}{c}\text { Disagree/ } \\
\text { Ineffective }\end{array}$ & $\begin{array}{c}\text { Strongly Disagree/ } \\
\text { Very ineffective }\end{array}$ \\
\hline RCF & 6 & 20 & 6 & 1 & 0 \\
& $(18 \%)$ & $(61 \%)$ & $(18 \%)$ & $(3 \%)$ & $(0 \%)$ \\
\hline Rep & 7 & 13 & 10 & 3 & 0 \\
& $(21 \%)$ & $(40 \%)$ & $(30 \%)$ & $(9 \%)$ & $(0 \%)$ \\
\hline E & 11 & 14 & 7 & 1 & 0 \\
& $(33 \%)$ & $(43 \%)$ & $(21 \%)$ & $(3 \%)$ & $(0 \%)$ \\
\hline EC & 2 & 13 & 11 & 5 & 2 \\
& $(6 \%)$ & $(40 \%)$ & $(33 \%)$ & $(15 \%)$ & $(6 \%)$ \\
\hline MF & 0 & 2 & 14 & 8 & 9 \\
& $(0 \%)$ & $(6 \%)$ & $(43 \%)$ & $(24 \%)$ & $(27 \%)$ \\
\hline Rec & 5 & 17 & 9 & 2 & 0 \\
& $(15 \%)$ & $(52 \%)$ & $(27 \%)$ & $(6 \%)$ & $(0 \%)$ \\
\hline CR & 2 & 7 & 15 & 4 & 5 \\
& $(6 \%)$ & $(21 \%)$ & $(46 \%)$ & $(12 \%)$ & $(15 \%)$ \\
\hline
\end{tabular}

Note: RCF=Receiving Corrective Feedback; Rep=Repetition; E=Elicitation; $\quad \mathrm{EC}=$ Explicit Correction; $\mathrm{MF}=$ Metalinguistic Feedback; Rec $=$ Recasts; $\mathrm{CR}=$ Clarification Requests

Next, Table 10 shows the aggregated points for each questionnaire item, based on which the learners' attitudes towards receiving CF in general and towards the six different types of CF can be interpret.

Table 10

Aggregated Points of Each Questionnaire Item

\begin{tabular}{cccccccc}
\hline & RCF & Rep & E & EC & MF & Rec & CR \\
\hline$P$ & 130 & 123 & 134 & 107 & 75 & 124 & 96 \\
\hline
\end{tabular}

Note: $\mathrm{P}=$ Points; $\mathrm{RCF}=$ Receiving Corrective Feedback; Rep=Repetition; E=Elicitation; $\mathrm{EC}=$ Explicit Correction; $\mathrm{MF}=$ Metalinguistic Feedback; Rec=Recasts; $\mathrm{CR}=$ Clarification Requests

It can be seen in the table, overall the students from the treatment group held positive attitudes towards receiving $\mathrm{CF}(\mathrm{P}=130$ for $\mathrm{RCF})$. The results showing general positive attitudes of students towards receiving $\mathrm{CF}$ in this study are consistent with the findings reported in other studies, such as Li (2017) and Zhu \& Wang (2019). More specifically, the students in the treatment group of this study regarded elicitation $(\mathrm{P}=134)$ as the most effective $\mathrm{CF}$ type, and metalinguistic feedback $(\mathrm{P}=75)$ as the most ineffective type, which interestingly mirrors the two types of CF used the most and the least respectively by their teacher. It seems to suggest that the teacher's choices in the use of CF types in the classroom may influence the students' preferences of different types of CF.

Apart from elicitation and metalinguistic feedback, results from the questionnaire also show that recasts $(\mathrm{P}=124)$ and repetition $(\mathrm{P}=123)$ were regarded by these student participants as the second and third most effective $\mathrm{CF}$ type, while explicit correction $(\mathrm{P}=107)$ and clarification requests $(\mathrm{P}=96)$ are ranked in the fourth and fifth places. Like elicitation, repetition is a kind of output pushing CF type giving the learner an opportunity to negotiate the correct form and do self-repair. As the students in this study are adult learners with an intermediate level of proficiency in the target language, they are more likely to prefer repetition to explicit correction because repetition is an indirect and self-repair feedback type which gives them time to test and revise their 
hypotheses about the target language ( $\mathrm{Li} \&$ Vuono, 2019) and eventually do the self-repair. However, for clarification requests, although they belong to output pushing CF type, learners may need metacognitive knowledge of the grammatical item (the English articles) in order for them to be able to clarify their choices of the articles. This may be the reason why clarification requests were the second least preferred type of CF for this group of students who would likely find the need to give explanations/clarifications of their choices challenging.

With regard to the results from semi-structured interviews, all five students from the treatment group who were interviewed gave positive replies to the first interview question: "Do you like the teacher's feedback? Why?" Their responses were consistent with the findings from the questionnaire, i.e., the learners in general held positive attitudes towards receiving $\mathrm{CF}$. The students viewed the teacher's feedback as "a timely response" (Student1) to "find out the mistake and correct it in time" (Student4). One of the students interviewed found the teacher's feedback helpful when it helped her "know (her) mistakes exactly" so that she would not "make the same mistakes any more" (Student 2). Another student believed that the teacher's feedback contributed to the efficiency of the lesson (Student 3). The teacher's feedback was also seen as "effective" and "helpful for learning" (Student 5).

For the second interview question, "Which kind of feedback do you like most? Please list some reasons." three of the five participants preferred elicitation most, and the other two students preferred recasts most. Their responses were also consistent with the findings from the questionnaire, i.e., elicitation was regarded as the most effective $\mathrm{CF}$ type and recasts ranked the second most effective CF type. The reasons for preferring elicitation most include its effectiveness (Student1), opportunity to reflect (Student4), and help for future performance (Student5), while the reasons for preferring recasts most include knowing the correct forms directly (Student2 \& Student3).

The third interview question, on the other hand, asks about their least preferred type of CF: "Which kind of feedback do you like least? Please list some reasons." Three of them responded that it was metalinguistic feedback. One response was explicit correction, and the last response was repetition. These responses were also consistent with the findings obtained from the questionnairemetalinguistic feedback was regarded as the most ineffective CF type, and repetition and explicit correction ranked the third and fourth most effective CF type respectively. The reasons for preferring metalinguistic feedback least highlighted the effect on the pace of lesson (e.g., "slow the teaching pace" Student 2 and "time-consuming" Student1). The reasons for preferring explicit correction and repetition less than, for example, elicitation are lack of opportunities for reflection (e.g., "listen without any thinking" Student4) and the time taken (e.g., "a waste of time" Student5).

\section{CONCLUSION}

This study examined the distributions and effectiveness of CF used by a Chinese university EFL teacher in relation to the learning of English articles by adult Chinese EFL learners. It also examined learners' attitudes towards receiving $\mathrm{CF}$ and different types of $\mathrm{CF}$. The findings from the study offer pedagogical implications for practitioners, especially those whose learners include adult Chinese EFL students.

Firstly, the notable lack of metalinguistic feedback in the teacher's uses of CF may need to be addressed. Studies such as Ellis et al. (2006) and Mohammadnia and Irandust (2015) have 
suggested that metalinguistic feedback can be more effective than recasts, as it provides comments, information or cues related to the well-formedness of the student's utterance without explicitly providing the correct form. The teacher in this study did not use this type of $\mathrm{CF}$, raising questions about her confidence or preference in providing such explicit comments, information or cues related to the well-formedness of the student's utterance. Using metalinguistic feedback may be seen as a potential disruption to the flow of lesson communication due to the attention paid to the comments, information or cues which may lead to digression from the sentence/item discussion for the teacher and the student. Nonetheless, its potential to generate a complex stimulus environment for learners to test and revise the hypotheses about the target language in a search for accurate structure should not be ignored. Therefore, there is a need for EFL teachers like the teacher participated in this study to receive appropriate $\mathrm{CF}$ training so that they can use various types of $\mathrm{CF}$ more confidently in the classroom. For example, training programmes for pre-service and in-service teachers could include sessions on CF practices. With better awareness of different $\mathrm{CF}$ types and their effectiveness, EFL teachers could reflect on their own practices in the classroom and make more informed decisions while keeping in mind contextual factors including students' age and level.

The findings from this study in relation to students' attitudes towards receiving CF and their preferences to different types of $\mathrm{CF}$ also suggest some implications for practitioners whose language classrooms include linguistically and culturally diverse learners. This study indicates that this group of Chinese adult EFL learners' preferences of different types of CF were dissimilar to those of EFL learners from other contexts. While the Japanese EFL learners in Yoshida's (2008) study reported that they preferred prompts and the Iranian EFL learners in Mohammadnia and Irandust's (2015) study preferred metalinguistic feedback the most, the Chinese EFL learners in this study preferred elicitation the most and metalinguistic feedback the least. Awareness of CF practices in learners' home context and their preference as well as possible unfamiliarity with certain types of CF might help practitioners to make better informed decisions in their classroom and adapt their teaching practices to help these learners adapt to the use of other different CF types.

It is acknowledged that there are limitations to this study. First, only two university EFL teachers and 67 adult EFL learners participated in the study. This rather small sample size may not represent the entire target population of Chinese university EFL students well and makes it impossible to generalize the findings of this study to other EFL classrooms in Mainland China. Second, the two teachers were not observed to ascertain whether they provided $\mathrm{CF}$ as their regular in-class conduct before the study took place. Considering the complexity and multi-dimensionality of $\mathrm{CF}$, more research needs to be done to gain a fuller understanding of CF practices and the mediating role of contextual factors in a range of contexts.

\section{REFERENCES}

Ammar, A., \& Spada, N. (2006). One size fits all?: Recasts, prompts, and L2 learning. Studies in Second Language Acquisition, 28(4), 543-574. https://doi.org/10.1017/S0272263106060268

Brown, A. (2009). Students' and teachers' perceptions of effective foreign language teaching: A comparison of ideals. The Modern Language Journal, 93(1), 46-60. https://doi.org/10.1111/j.1540-4781.2009.00827.x 
Brown, D. (2016). The type and linguistic foci of oral corrective feedback in the L2 classroom: A meta-analysis. Language Teaching Research, 20(4), 436-458. https://doi.org/10.1177/1362168814563200

Chrabaszcz, A. \& Jiang, N. (2014). The role of the native language in the use of the English nongeneric definite article by L2 learners: A cross-linguistic comparison. Second Language Research, 30(3), 351-379. https://doi.org/10.1177/0267658313493432

Crosthwaite, P. (2016). L2 English article use by L1 speakers of article-less languages: A learner corpus study. International Journal of Learner Corpus Research, 2(1), 68-100. https://doi.org/10.1075/ijlcr.2.1.03cro

Dörnyei, Z. (2007). Research Methods in Applied Linguistics. OUP.

Ellis, R. (2006). Researching the effects of form-focused instruction on L2 acquisition. AILA Review, 19(1), 18-41. https://doi.org/10.1075/aila.19.04ell

Ellis, R., Loewen, S., \& Erlam, R. (2006). Implicit and explicit corrective feedback and the acquisition of L2 grammar. Studies in Second Language Acquisition, 28(3), 339-368. https://doi.org/10.1017/S0272263106060141

Erlam, R., Ellis, R. \& Batstone, R. (2013). Oral corrective feedback on L2 writing: Two $\begin{array}{llll}\text { approaches } \quad \text { compared. } & \text { System, }\end{array}$ http://doi.org/0.1016/J.SYSTEM.2013.03.004

Gooch, R., Saito, K, \& Lyster, R. (2016). Effects of recasts and prompts on L2 pronunciation development: Teaching English /ג/ to Korean adult EFL learners. System, 60, 117-127. http://doi.org/10.1016/j.system.2016.06.007

Ha, X.V., \& Murray, J. (2020). Corrective feedback: Beliefs and practices of Vietnamese primary EFL teachers. Language Teaching Research. https://doi.org/10.1177/1362168820931897

Li, S. (2017). Teacher and learner beliefs about corrective feedback. In H. Nassaji \& E. Kartchava (Eds.), Corrective feedback in second language teaching and learning (pp. 143-157). Routledge.

Li, S. (2018). Data collection in the research on the effectiveness of corrective feedback: A synthetic and critical review. In A. Gudmestad, \& A. Edmonds (Eds.), Critical reflections on data in second language acquisition (pp. 33-62). John Benjamins.

Li, S., \& Vuono, A. (2019). Twenty-five years of research on oral and written corrective feedback in System. System, 84, 93-109. http://doi.org/10.1016/j.system.2019.05.006

Liu, D., \& Gleason, J. (2002). Acquisition of the article the by nonnative speakers of English. Studies in Second Language Acquisition, 24(1), 1-26. https://doi.org/10.1017/S0272263102001018

Llinares, A. \& Lyster, R. (2014). The influence of context on patterns of corrective feedback and learner uptake: A comparison of CLIL and immersion classrooms. The Language Learning Journal, 42(2), 181-194. https://doi.org/10.1080/09571736.2014.889509

Lyster, R., \& Ranta, L. (1997). Corrective feedback and learner uptake: Negotiation of form in communicative classrooms. Studies in Second Language Acquisition, 19(1), 37-66. https://doi.org/10.1017/S0272263197001034

Lyster, R., Saito, K., \& Sato, M. (2013). Oral corrective feedback in second language classrooms. Language Teaching, 46(1), 1-40. https://doi.org/10.1017/S0261444812000365

Mohammadnia, Z., \& Irandust, F. (2015). Iranian EFL learners' attitudes towards corrective feedback and teachers' practices. International Journal of Research in Social Sciences, 5(1), 868-885. 
Ranta, L., \& Lyster, R. (2007). A cognitive approach to improving immersion students' oral language abilities: The Awareness-Practice-Feedback sequence. In R. Dekeyser (Eds.), Practice in a second language: Perspectives from applied linguistics and cognitive psychology (pp. 141-160). Cambridge University Press.

Sheen, Y. (2007). The effects of corrective feedback, language aptitude and learner attitudes on the acquisition of English articles. In A. Mackey (Eds.), Conversational interaction in second language acquisition: A collection of empirical studies (pp. 301-322). OUP.

Wang, W. \& Li, S. (2021). Corrective feedback and learner uptake in American ESL and Chinese EFL classrooms: A comparative study. Language, Culture and Curriculum, 34(1), 35-50. https://doi.org/10.1080/07908318.2020.1767124

$\mathrm{Xu}, \mathrm{S}$. (2012). An investigation into teachers' corrective feedback in Chinese EFL classrooms. Chinese Journal of Applied Linguistics, 35(4), 480-505. https://doi.org/10.1515/cjal-20120035

Yang, Y. (2009). Feedback and uptake in Chinese EFL classrooms: In search of instructional variables. The Journal of ASIA TEFL, 6(1), 1-22.

Yang, Y., \& Lyster, R. (2010). Effects of form-focused practice and feedback on Chinese EFL learners' acquisition of regular and irregular past tense forms. Studies in Second Language Acquisition, 32(2), 235-263. https://doi.org/10.1017/S0272263109990519

Yilmaz, Y. (2013). The relative effectiveness of mixed, explicit and implicit feedback in the acquisition of English articles. System, 41(3), 691-705. https://doi.org/10.1016/j.system.2013.07.020

Yoshida, R. (2008). Teachers' choice and learners' preference of corrective-feedback types. Language Awareness, 17(1), 78-93. https://doi.org/10.2167/la429.0

Zhang, L. J., \& Rahimi, M. (2014). EFL learners' anxiety level and their beliefs about corrective feedback in oral communication classes. System, 42, 429-439. http://dx.doi.org/10.1016/j.system.2014.01.012

Zhu, Y. \& Wang, B. (2019). Investigating English language learners' beliefs about oral corrective feedback at Chinese universities: A large-scale survey. Language Awareness, 28(2), 139161. https://doi.org/10.1080/09658416.2019.1620755 


\section{APPENDIX A Questionnaire (adapted from Zhang \& Rahimi, 2014)}

Instructions: Please tick the most appropriate response. Make sure to mark only one. If you need help to understand the English in this questionnaire or have any question, you can ask the researcher to explain or answer it to you in Chinese verbally or you may use the dictionaries.

1. I want to receive corrective feedback (e.g., provide a hint for me to self-correct, tell me that I made an error, or correct my error) when I make mistakes.
A. Strongly Agree
B. Agree
$\begin{array}{lll}\text { C. Neutral } & \text { D. Disagree }\end{array}$
E. Strongly Disagree

How do you rate each type of oral error correction below?

2. Student: Yesterday I found a dog in the street and I took a dog home.

Teacher: I took a dog home?

(Repetition: The teacher repeats (part of) what the student said with an emphasis on the student's grammatical error by changing his/her tone of voice)
A. Very Effective
B. Effective
C. Neutral
D. Ineffective E. Very Ineffective

3. Student: Yesterday I found a dog in the street and I took a dog home.

Teacher: I took...

(Elicitation: The teacher asks the students to correct and complete the sentence.)

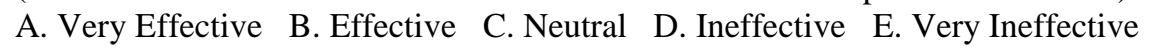

4. Student: Yesterday I found a dog in the street and I took a dog home.

Teacher: The second "dog" is already mentioned. You need to use the definite article "the" here.

(Explicit Correction: The teacher gives the correct form to the student with a grammatical explanation.)

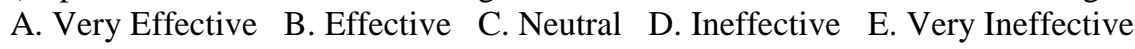

5. Student: Yesterday I found a dog in the street and I took a dog home.

Teacher: What kind of articles should we use when we talk about something that we have already mentioned? (Metalinguistic feedback: The teacher gives a hint or a clue without specifically pointing out the mistake.)
A. Very Effective
B. Effective
C. Neutral
D. Ineffective
E. Very Ineffective

6. Student: Yesterday I found a dog in the street and I took a dog home.

Teacher: I took the dog home. (Recasts: The teacher repeats the student's utterance in the correct form without pointing out the student's error.)
A. Very Effective
B. Effective
C. Neutral
D. Ineffective
E. Very Ineffective

7. Student: Yesterday I found a dog in the street and I took a dog home.

Teacher: Pardon? What do you mean by 'took a dog home'?

(Clarification request: The teacher indicates to the student either that his/her utterance has been misunderstood or that the utterance is ill formed in some way.)
A. Very Effective
B. Effective
C. Neutral
D. Ineffective
E. Very Ineffective 